ABDI: Jurnal Pengabdian dan Pemberdayaan Masyarakat ISSN: 2656-369X (Print), 2684-8570 (Online)

Volume 3 No. 1, Juni 2021

http://abdi.ppj.unp.ac.id/index.php/abdi

Email: abdi@ppj.unp.ac.id

DOI: https://doi.org/10.24036/abdi.v3il.85

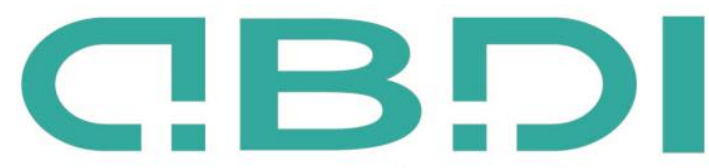

ABDI: JURNAL PENGABDIAN DAN PEMBERDAYAAN MASYARAKAT

\title{
Usaha Rendang Rumahan Untuk Meningkatkan Perekonomian Keluarga di Kelurahan Padang Tangah Payobadar Kecamatan Payakumbuh Timur
}

\author{
Rusdi Rusdi $^{1}$, Wahidul Basri ${ }^{2}$, Etmi Hardi ${ }^{3}$, Heffi Alberida ${ }^{4}$ \\ 1,2,3 Jurusan Sejarah, Universitas Negeri Padang \\ ${ }^{4} J u r u s a n$ Biologi, Universitas Negeri Padang
}

email: $\underline{\text { rusdi64@fis.unp.ac.id, wahidulsejarahunp@gmail.com, etmihardi@yahoo.co.id, alberidamatua@gmail.com }}$

\begin{abstract}
Abstrak
Permasalahan mitra PKM sebagai pengusaha mikro yang bergerak dalam bidang usaha rendang skala kecil masih bersifat tradisional baik dari segi peralatan, manajemen, maupun pemasaran. Untuk itu, perlu pengembangan peralatan, pemasaran, manajemen, bantuan permodalan dan perlu pendampingan untuk memulai usaha. Metode kegiatan dengan skema pelaksanaan program Ipteks yang dilakukan bersama mitra difokuskan pada dua bidang, yaitu penerapan teknologi tepat guna, perbaikan manajemen usaha dan pemasaran. Kegiatan perbaikan manajemen usaha dan pemasaran diwujudkan dalam bentuk pelatihan. Hasil Pengabdian berupa Pelatihan usaha rendang di Kelurahan Padang Tangah Payobadar Kecamatan Payakumbuh Timur mendapat respon cukup positif dari masyarakat. Hal ini nampak dari antusiasnya para Ibu-Ibu yang mengikuti kegiatan dari awal sampai kegiatan berakhir. Usaha rendang rumahan oleh kelompok Mitra Pengabdian UNP yang diketuai oleh Ibuk Yurdalis bisa berkembang kalau dilaksanakan dengan penuh ketelatenan dan kesabaran dengan tidak hanya mengandalkan pesanan akan tetapi juga mengupayakan pemasaran secara online melalui berbagai media sosial.
\end{abstract}

Kata Kunci: Perekonomian Keluarga; Rendang Rumahan; Usaha

\section{Abstract}

The problems with PKM partners as micro entrepreneurs engaged in small-scale rendang business are still traditional in terms of equipment, management, and marketing. For that, it needs equipment development, marketing, management, capital assistance and assistance to start a business. The method of activities with the science and technology program implementation scheme that is carried out with partners is focused on two areas, namely the application of appropriate technology, improvement of business management and marketing. Marketing and business management improvement activities are manifested in the form of training. The results of the Community Service in the form of rendang business training in the Padang Tangah Payobadar Village, East Payakumbuh Subdistrict, received quite a positive response from the community. This can be seen from the enthusiasm of the mothers who participated in the activity from the beginning to the end of the activity. The home rendang business by the UNP Community Partners group chaired by Ibuk Yurdalis can develop if it is carried out with full diligence and patience by not only relying on orders but also seeking online marketing through various social media.

Keyword: Effort; Family Economy; Rendang

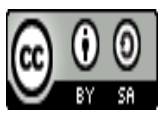

Received: 26 November $2020 \quad$ Revised: 12 Maret $2021 \quad$ Available Online: 15 Maret 2021


Rusdi Rusdi, Wahidul Basri, Etmi Hardi, Heffi Alberida Usaha Rendang Rumahan Untuk Meningkatkan Perekonomian Keluarga di Kelurahan Padang Tangah Payobadar Kecamatan Payakumbuh Timur

\section{Pendahuluan}

Sejarah rendang, tidak ada yang tahu secara tepat kapan dan di mana rendang tercipta, peneliti Wynda mengatakan rendang sudah ada sejak abad ke-16. Sebuah catatan harian Kolonel Stuers 1827 tentang kuliner menyebutkan deskripsi kuliner secara implisit diduga mengarah pada rendang. Sebuah literatur yang ditulis pada abad ke-19 menceritakan, masyarakat Minang di daerah darek (darat) biasa melakukan perjalanan menuju Selat Malaka hingga ke Singapura yang memakan waktu sampai satu bulan melewati sungai (Hanafiah, Saputra, \& Ramadhanty, 2019). Karena sepanjang jalan tidak ada perkampungan, para perantau menyiapkan bekal yang tahan lama. Dari sinilah tercipta masakan rendang dengan waktu proses perandangan yang lama, yang menciptakan masakan yang tahan lama pula.

Rendang, kuliner Minangkabau termasuk kuliner yang enak dan lezat di setiap lidah etnis manusia. Hal ini dibuktikan dengan dirilisnya survei oleh CNN Internasional yang menyatakan bahwa rendang meraih urutan pertama dalam World's 50 Delicious Food. Masakan rendang ini memiliki kaitan atau relevansi dengan budaya merantau orang Minangkabau. Jika di Ranah Minang rendang identik dengan masakan yang kering dan menghitam, tidak demikian dengan di tanah rantau. Rendang mengalami perubahan tekstur, cita-rasa, dan bumbu. Rendang yang sering ditemui di luar daerah Minangkabau (Sumatera Barat) bukanlah rendang yang dimaknai oleh orang Minang asli. Melainkan, rendang yang di tanah rantau tersebut adalah kalio. Secara sederhana, proses memasak menuju rendang terdiri dari tiga tahapan, yaitu gulai daging - kalio - rendang (Wynda, 2019).

Hal lain yang patut diketahui adalah rendang memiliki posisi terhormat dalam adat Minangkabau. Bahan-bahan rendang memiliki makna tersendiri. Daging sapi sebagai bahan utama rendang melambangkan niniak mamak dan bundo kandung, yang dipercaya akan memberikan kemakmuran. Kelapa atau karambia melambangkan kaum intelektual atau dalam bahasa Minang disebut cadiak pandai, yang menjadi simbol perekat kebersamaan. Yang terakhir adalah lado atau sambal. Sambal dinilai sebagai representasi alim ulama yang tegas dalam mengajarkan agama, sungguh rendang sangat kaya makna.

Dalam proses memasak rendang, diketahui tentang dapur kuno keluarga Minang. Mitos bahwa rumah panggung tak punya dapur di dalam rumah berhasil dipecahkan. Merandang atau membuat rendang bukanlah proses yang sebentar, tetapi dapur itu utuh hingga zaman sekarang. Ketika rendang merajai ranking World's 50 Best Food 2017 keluaran CNN Travel, bikin kita bangga, maka tugas selanjutnya adalah mempertahankan posisi itu (Suri, 2012). Rendang memang memiliki cita rasa yang khas. Santannya yang gurih serta bumbunya yang legit dan pedas sangat memanjakan lidah para penikmatnya. Tak heran rendang dinobatkan menjadi masakan terenak sedunia oleh CNN Go. Lebih dari 35.000 orang dari seluruh dunia menyatakan rendang adalah makanan terlezat sejagad raya (Utomo, 2012).

Membuat rendang memang membutuhkan waktu lama dan ketelatenan. Namun dengan modifikasi resep, membuat rendang pun menjadi lebih cepat dan tak sesulit yang dibayangkan. Bermacam bahan dasar hewani maupun nabati dapat diolah menjadi rendang yang lezat. Bukan hanya daging sapi dan ayam yang dapat dibuat rendang, aneka seafood, dan bermacam jenis sayuran pun bisa. Cobalah membuat Rendang Daging, Rendang Paru, Rendang Ayam, Rendang Jantung/ Usus/Ceker Ayam, Rendang Tuna, dan Rendang Kepiting. Dan jangan ragu untuk mencoba Rendang Kacang Merah, Rendang Tempe, Rendang Basah Nangka, Rendang Basah Buncis, Terung Bumbu Rendang, dan Rendang Jengkol. Semuanya mengandung gizi dan bisa menjadi menu favorit keluarga. Dengan beragam pilihan rendang yang tidak banyak dijumpai di pasaran, aneka olahan rendang ini juga bisa dimasukkan dalam menu usaha rendang (Erwin, 2013).

Sebenarnya rendang sudah ada sejak jaman dahulu meski demikian masakan rendang hingga saat ini masih saja tetap populer di masyarakat. Sehingga tak heran bila banyak masyarakat yang memanfaatkan olahan rendang sebagai kesempatan bisnis untuk menambah penghasilan tambahan. Apalagi saat ini banyak masyarakat yang menggemari olahan rendang hingga membuat potensi usaha rendang dapat dimanfaatkan sebagai ladang usaha yang cukup menjanjikan. Peluang usaha rendang 
Rusdi Rusdi, Wahidul Basri, Etmi Hardi, Heffi Alberida Usaha Rendang Rumahan Untuk Meningkatkan Perekonomian Keluarga di Kelurahan Padang Tangah Payobadar Kecamatan Payakumbuh Timur

kini juga masih terbuka sangat luas bagi yang ingin menggeluti kegiatan usaha ini. Usaha rendang bisa dijalankan dengan cara yang sangat mudah dan tidak perlu mengeluarkan modal yang besar sehingga bisa mengawali usaha rendang dalam skala kecil.

Di tempat mitra PKM, yakni di Padang Tangah Payobadar Kecamatan Payakumbuh Timur, ada ibu-ibu yang sudah melakukan usaha rendang secara rumahan, diantaranya adalah Ibu Yurdalis yang sudah memulai usaha rendangnya secara kecil-kecilan. Dia memasak rendangnya kalau ada pesanan dari tetangga atau dari orang-orang sekitar kampung tersebut, jadi usaha rendangnya boleh dikatan tidak rutin, tetapi tergantung pemesanan dari orang-orang sekitar. Dengan demikian, usaha rendang rumahan ini tidak bisa berkembang dengan baik, terkendala peralatan, manajemen, pemasaran dan permodalan. Mitra yang lain adalah Ibu Rosa Weliana, ia adalah seorang ibu yang sangat berminat untuk berusaha rendang ini, tatapi terkendala permodalam dan sampai saat ini ia hanya bekerja menjadi juru masak di salah satu rumah makan di daerah tersebut. Jadi ke dua mitra PKM ini sangat berpotensi untuk dikembangkan dalam bidang usaha rendang rumahan.

Dalam Program Kemitraan Masyarakat (PKM) ini, tim pengabdian ingin meningkatkan usaha rendang pada mitra di Kelurahan Padang Tangah Payobadar Kecamatan Payakumbuh Timur dengan pertimbangan, usaha rendang memiliki peluang yang menjanjikan, antara lain: (1) Rendang adalah makanan yang disukai semua orang. Kepopulerannya sudah menjadi bukti bahwa rendang tidak hanya cocok untuk lidah masyarakat lokal tapi juga mancanegara; (2) Rendang adalah salah satu jenis makanan yang tahan lama meskipun tidak dimasak dengan menggunakan pengawet; (3) Prospek usaha rendang, Prospek usaha rendang cukup bagus, meski keberadaan usaha rendang sudah ada sejak lama namun tetap membuat peminat rendang tidak pernah surut, bahkan dari waktu ke waktu akan terus bertambah sehingga membuat usaha rendang mampu mendatangkan keuntungan; (4) Konsumen usaha rendang, dengan membuat rendang dengan cita rasa yang enak dan nikmat sehingga mampu menarik minat dari berbagai kalangan. Konsumen rendang kinipun mencangkup semua kalangan, mulai dari kalangan anak-anak bahkan hingga orang dewasa juga menyukainya; (5) Bahan baku rendang, Berbagai bahan baku yang dibutuhkan untuk mengolah rendang diantaranya daging sapi, bumbu rempah, santan kelapa dan berbagai bahan yang lain. Untuk mendapatkan bahan baku rendang sendiri memang sangat mudah, karena rendang kini bisa didapatkan dimana-mana bahkan mulai dipasaran hingga di supermarket; (6) Harga jual rendang, Harga rendang dapat ditentukan sesuai harga yang kini sudah ada di pasaran. Dalam menentukan harga jual olahan rendang memang disarankan jangan terlalu mahal karena konsumen akan lebih menyukai makanan dengan harga yang terjangkau namun tetap memiliki cita rasa yang enak. Pematokan harga rendang biasanya sekitar Rp. 15.000 per porsi. Dari analisa sistuasi di atas jelas sekali bahwa usaha rendang rumahan, dalam situasi pandemi covid-19 ini mempunyai prospek yang cukup baik dan sangat layak untuk dilakukan oleh ibu-ibu rumah tangga yang dianjurkan untuk tinggal di rumah saja.

Permasalahan mitra sebagai pengusaha mikro yang bergerak dalam bidang usaha rendang rumahan dalam pelaksanaan usahanya masih bersifat tradisional, dan belum menerapkan manajemen yang baik. Untuk itu, perlu pengembangan usaha rendangnya dengan peralatan, manajemen dan pemasaran yang modern, disamping itu perlu pendampingan dan permodalan untuk memulai usaha rendang rumahan.

\section{Metode Pelaksanaan}

Melalui Program Kemitraan Masyarakat (PKM) ini dan berdasarkan analisis kebutuhan yang telah dilaksanakan, tim pengabdi menawarkan solusi terhadap permasalahan tersebut dengan sentuhan Ipteks. Skema pelaksanaan kegiatan program Ipteks yang dilakukan bersama mitra difokuskan pada dua bidang, yaitu penerapan teknologi tepat guna dan perbaikan manajemen usaha serta pemasaran. Kegiatan perbaikan manajemen dan pemasaran diwujudkan dalam bentuk pelatihan.

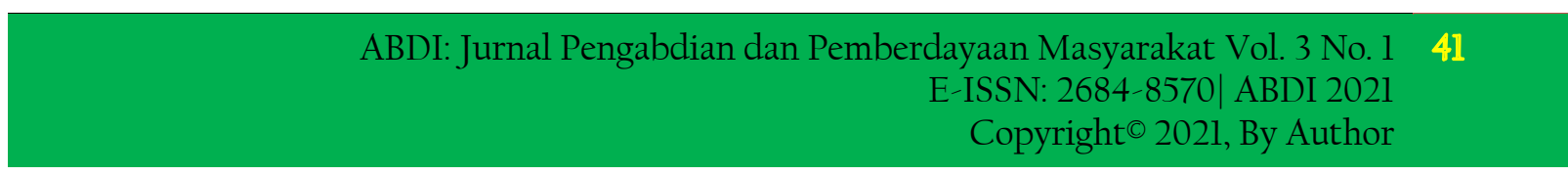


Rusdi Rusdi, Wahidul Basri, Etmi Hardi, Heffi Alberida Usaha Rendang Rumahan Untuk Meningkatkan Perekonomian Keluarga di Kelurahan Padang Tangah Payobadar Kecamatan Payakumbuh Timur

\section{Hasil dan Pembahasan}

\subsection{Solusi Usaha Rendang Rumahan}

\subsubsection{Cara Memasak Rendang Yang Enak}

Memasak rendang memang susah-susah gampang, ada beberapa cara yang bisa digunakan untuk memasak rendang lezat tanpa khawatir gagal: (a) Pilih daging yang tepat. Memilih daging bagian yang padat seperti paha luar adalah opsi terbaik memasak rendang yang enak, selain keras daging paha juga sedikit mengandung lemak. Hal yang tak kalah penting adalah memastikan kesegaran daging yang akan dimasak. Daging segar biasanya memiliki rona warna merah terang; (b) Perhatikan proses pengolahannya. Bumbu yang digunakan sangat menentukan hasil akhir racikan rendang. Untuk menjaga cita rasa dan kesegaran bumbu, disarankan untuk menggilingnya dengan tangan; (c) Perhatikan takaran santannya, Untuk mendapatkan tekstur serta rasa rendang yang pas, menakar santan adalah kunci terpenting. Jika santan kurang, rendang akan terasa kurang enak dan bumbunnya akan encer atau terlalu sedikit. Perbandingan daging dengan santan yang umum digunakan adalah 1:3. Artinya untuk 1 kilo gram daging memerlukan santan kental dari 3 butir kelapa. Untuk membuat rendang pedas, 1 kilo gram daging memerlukan kurang lebih 250 gram cabai dan santan kental yang diambil dari 4 butir kelapa; (d) Perhatikan api yang digunakan untuk memasak, Rendang yang lezat adalah rendang yang dagingnya empuk, mudah digigit dengan bumbu yang meresap hingga ke serat. Untuk bisa mendapatkan rasa rendang seperti itu dengan menggunakan api kecil. Untuk rendang basah, waktu masak yang diperlukan kurang lebih 4 jam. Sementara untuk rendang kering biasanya akan selesai dimasak dalam waktu sekitar 5-6 jam; (e) Perhatikan cara mengaduk rendangnya, Memasak rendang memang mengandalkan teknik mengaduk. Bukan sembarang mengaduk, rendang tidak boleh diaduk terlalu sering tapi juga tidak boleh dibiarkan begitu saja. Ketika daging sudah dimasukkan, rendang tidak boleh diaduk terlalu sering karena potongannya bisa pecah, juga harus memastikan bagian dasar wajan tidak lengket dengan mengaduknya perlahan-lahan.

\subsubsection{Kiat Usaha Rendang Rumahan}

Untuk usaha rendang rumahan tidak harus punya rumah makan Padang untuk berjualan rendang. Ada banyak orang yang berhasil sukses dengan usaha makanan rumahan. Rendang bisa menjadi pilihan yang tepat untuk memulai usaha di rumah. Ada beberapa kiat bagi yang ingin memulai usaha rendang rumahan: (a) Mulai dengan produksi kecil. Banyak usaha rumahan memulai langkah dari berjualan dalam jumlah kecil. Untuk langkah awal, coba tawarkan rendang racikan ketetangga, keluarga atau rekan sejawat. Ketika responnya dirasa cukup baik, mulailah menawarkan secara online atau mungkin beriklan; (b) Buat nama dan packaging yang menarik. Ada banyak jenis makanan yang terdengar biasa namun berhasil dijual dengan nilai tinggi karena nama dan kemasannya menarik. Hal yang sama bisa dilakukan dengan rendang, buat merek yang menarik dengan kemasan kedap udara yang berkualitas. Tambahkan logo ciamik untuk memberikan kesan profesional dalam produk, ini merupakan langkah awal menarik minat calon konsumen; (c) Jangan abaikan perizinan. Usaha apapun termasuk usaha rendang rumahan memerlukan izin dari dinas terkait. Ini untuk memastikan produk yang kita jual sudah sesuai standar baik dari segi kesehatan maupun kehalalannya. Pastikan memenuhi kelengkapan dokumen yang diperlukan untuk menjalankan usaha rendang; (d) Jangan berhenti berinovasi. Selain membuat rendang dalam kemasan beragam dengan desain packaging menarik, cobalah berkreasi dengan bahan baku. Selain menggunakan daging sapi, juga bisa bereksperimen denga daging ayam, bebek, hingga jengkol, dengan adanya variasi ini tentu akan membuat pelanggan merasa senang. (https://blog.mokapos.com/resep-rendang-untuk-bisnis-rumahan)

\subsection{Hasil Kegiatan Pengabdian}

Pengabdian Kepada Masyarakat tentang: "Usaha Rendang Rumahan Untuk Meningkatkan Perekonomian Keluarga di Kelurahan Padang Tangah Payobadar Kecamatan Payakumbuh Timur", dilakukan dalam dua bagian kegiatan, yakni: (1) Pengadaan peralatan usaha rendang; (2) Pelatihan Pemasaran online usaha rendang. Kegiatan PKM dimulai pada tanggal 25-26 Juli 2020, tim 
Rusdi Rusdi, Wahidul Basri, Etmi Hardi, Heffi Alberida Usaha Rendang Rumahan Untuk Meningkatkan Perekonomian Keluarga di Kelurahan Padang Tangah Payobadar Kecamatan Payakumbuh Timur

pengabdian melakukan koordinasi dengan mitra pengabdian terkait dengan persiapan pengabdian. Kegiatan awal adalah diskusi dengan mitra untuk penentuan lokasi usaha rendang rumahan sekaligus membicarakan peralatan yang dibutuhkan untuk kegiatan serta tempat yang layak dan strategis untuk usaha rendang, agar mudah dilihat dan terletak di pinggir jalan raya, karena lokasi usaha merupakan bagian dari strategi pemasaran.

Pada pada tanggal 1-8-2020 Tim Pengabdian melakukan survei ke lokasi Rendang Tradisional Minang NIKMAT DIA, salah satu pengusaha rendang yang sudah cukup berhasil di Kota Payakumbuh. Usaha rendang ini sudah dimulai sejak tahun 2002 yang dilakukan oleh pasangan suami-istri yang bernama Bapak Adek dan Ibuk Dia. Survei ini bertujuan untuk menggali pengalaman bapak Adek dan Ibuk Dia dalam menjalankan usaha rendangnya sehingga bisa berkembang dan bertahan sampai saat ini. Pengalaman usaha ini dapat dijadikan masukan untuk pengembangan usaha rendang rumahan di lokasi mitra pengabdian. Selanjutnya tanggal 9-8-2020, mendesaian stiker sebagai label atau merek rendang, Untuk mendesain stiker usaha rendang dibantu oleh mahasiswa yang Husnul Fikri dan Haris. Husnul Fikri dan Haris mahasiswa yang dilibatkan dalam pengabdian sedang mendesain stiker atau label untuk merek rendang mitra pengabdian.

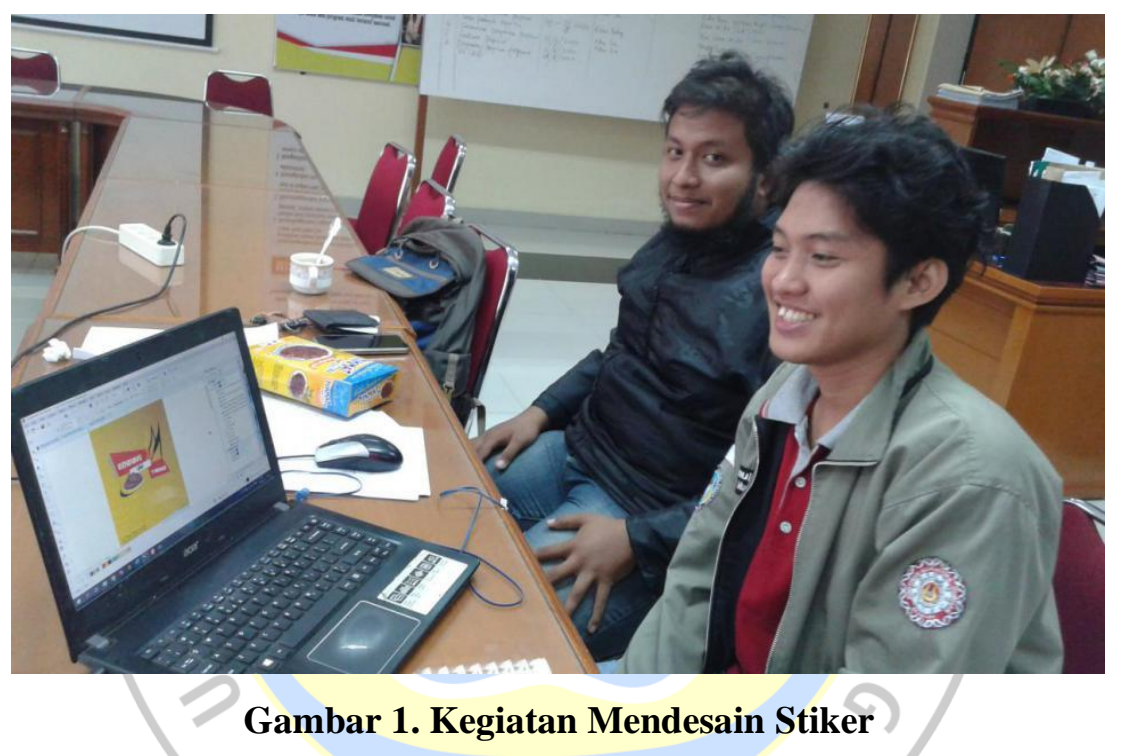

Sabtu, 15-8-2020 kegiatan dilanjutkan mendesain spanduk kegiatan usaha rendang, Spanduk kegiatan pengabdian kepada masyarakat ini juga mempunyai peranan penting dalam pelaksanaan kegiatan, agar dapat menyampaikan pesan kepada masyarakat bahwa sedang berlangsung kegiatan pengabdian kepada masyarakat yang dilakukan oleh tim dosen dari UNP.

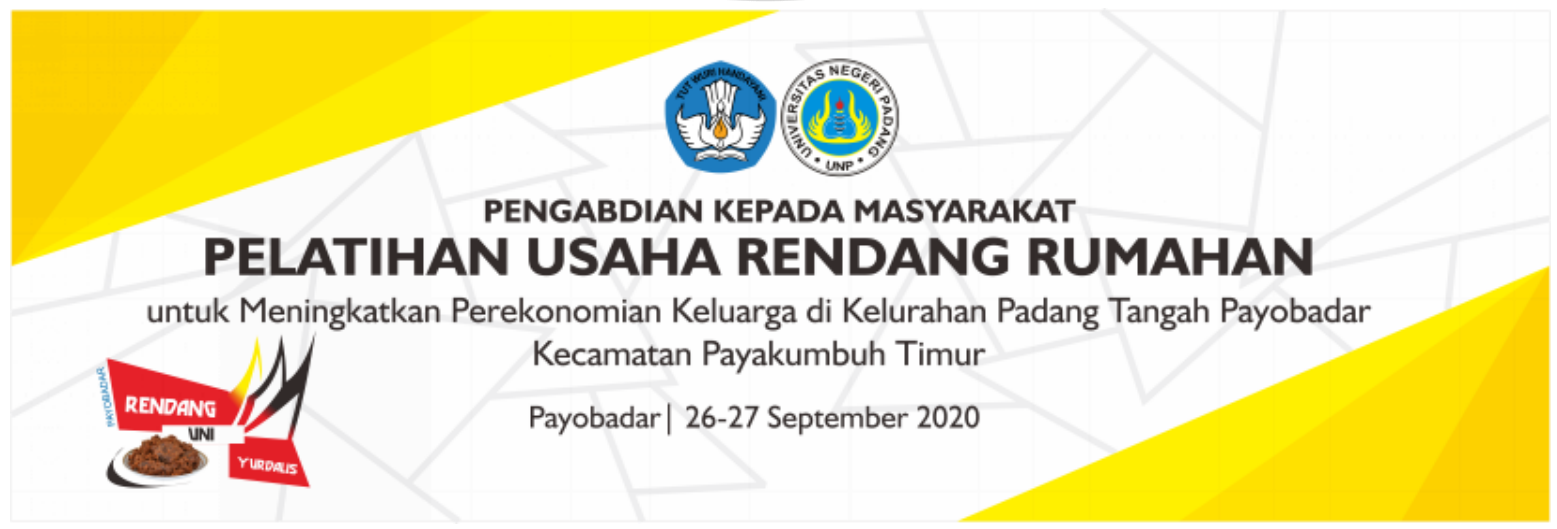

Gambar 2. Spanduk Kegiatan

ABDI: Jurnal Pengabdian dan Pemberdayaan Masyarakat Vol. 3 No. 1

E-ISSN: 2684-8570| ABDI 2021 
Rusdi Rusdi, Wahidul Basri, Etmi Hardi, Heffi Alberida Usaha Rendang Rumahan Untuk Meningkatkan Perekonomian Keluarga di Kelurahan Padang Tangah Payobadar Kecamatan Payakumbuh Timur

Pada tanggal 16-8-2020 adalah kegiatan membuat model pelatihan pemasaran online rendang, Untuk mendesain pemasaran online dibantu oleh mahasuswa, Angelina dan Sherly. Adapun hasil dari desain atau model pemasaran online rendang tersebut adalah sebagai berikut:

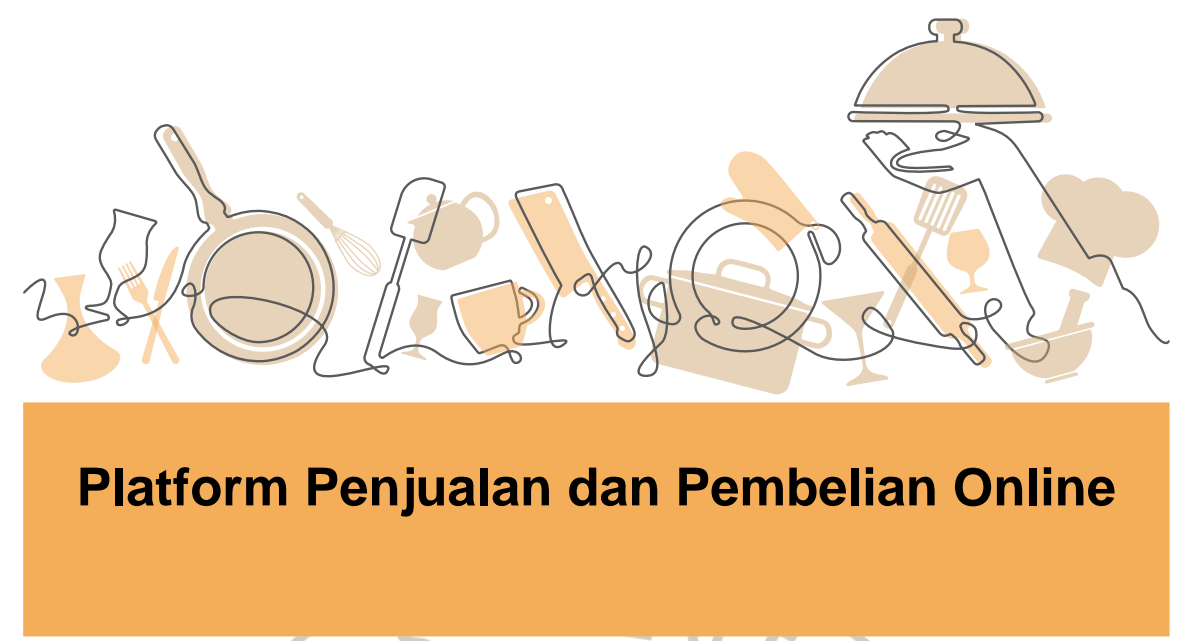

Gambar 3. Desain Pemasaran Online

Setelah desain selesai pada tanggal 22-8-2020 diadakan diskusi oleh tim dosen pengabdian dengan mahasiswa yang dilibatkan. Dari hasil diskusi tersebut didapatkan masukan-masukan baik dari tim dosen maupun mahasiswa untuk perbaikan model pemasaran online rendang.

Selanjutnya pada tanggal 17-9-2020 dilakukan pembelian alat utama untuk usaha rendang yakni kuali sebagai alat memasak rendang. Kuali yang dimaksud adalah kuali besi karena memasak dengan kuali besi akan menghasilkan masakan rendang yang berkualitas tinggi, karena kuali besi menyimpan panas yang lebih lama dibandingkan dengan kuali almunium. Setelah berkeliling Pasar Raya Padang, tim pengabdian menemukan satu toko yang menjual kuali besi tersebut yakni toko MHD GUFERTI yang menjual dagang pecah belah, yang beralamat di Jl. Sandang Pangan Pasar Bertingkat fase II los 1 No $10 \mathrm{Jl}$. Pasar Baru No. 38 Padang.

Kegiatan utama adalah pada hari Sabtu-Minggu 26-27-Sep 2020 dengan Pelaksanaan Pelatihan usaha rendang. Pada hari petama Sabtu 26-9-2020 adalah Persiapan, Tim Pengabdian berserta mahasiswa yang dilibatkan berangkat dari Kota Padang jam 10.00 WIB dan sampai di kota Payakumbuh sekitar jam 14.00. Lalu Tim Pengabdian langsung menuju ke lokasi mitra pengabdian yakni di Jl. Dt. Parpatih Nan Sabatang, Kelurahan Padang Tangah Payobadar Kecamatan Payakumbuh Timur. Di lokasi pengabdian tim pengabdi sudah ditunggu oleh Mitra pengabdian yang diketuai oleh Ibu Yurdalis. Setelah berkoordinasi dan berdiskusi dengan Mitra Pengabdian untuk mencek kesiapan pelaksanaan Pelatihahan usaha rendang, dari hasil koordinasi tersebut dan pengamatan, pelatihahan usaha rendang siap untuk dilaksanakan keesokan harinya.

Pada hari kedua Minggu 27-9-2020 adalah Pelaksanaan, Pelatihan usaha rendang ini dimulai jam 09.00 pagi. Kegiatan diawali oleh sambutan Ketua Pelaksana yakni bapak Dr. Wahidul Basri, M.Pd yang menjelaskan maksud dan tujuan pengabdian kepada masyarakat yang dilaksanakan oleh Tim Pengabdian UNP kepada para Ibu-Ibu peserta pelatihan. Beliau menjelaskan bahwa sebagai salah satu Tri Dharma Perguruan Tinggi maka tugas dosen adalah melaksanakan pengabdian kepada masyarakat. Tahun ini wilayah Kelurahan Padang Tangah Payobadar mendapat giliran untuk tempat pengabdian dosen tersebut. Sebelumnya tim pengabdian UNP telah melakukan survei kepada masyarakat yang akan dijadikan mitra pengabdian, maka terpilihlah kelompok Mitra yang diketuai oleh Ibu Yurdalis. Selanjutnya pelaksanaan kegiatan pengabdian kepada masyarakat ini, dijelaskan bahwa, karena kondisi masih dalam ancaman wabah covid-19, maka aturan protocol covid dari pemerintah dan dari UNP harus dijalankan, seperti memakai masker, jaga jarak dan cuci tangan dan 
Rusdi Rusdi, Wahidul Basri, Etmi Hardi, Heffi Alberida Usaha Rendang Rumahan Untuk Meningkatkan Perekonomian Keluarga di Kelurahan Padang Tangah Payobadar Kecamatan Payakumbuh Timur

alhamdulillah semua peserta telah mentaati aturan tersebut. Oleh karena itu juga pelatihan ini sengaja tidak mengundang banyak perserta, yang diundang sekitar 20 orang.

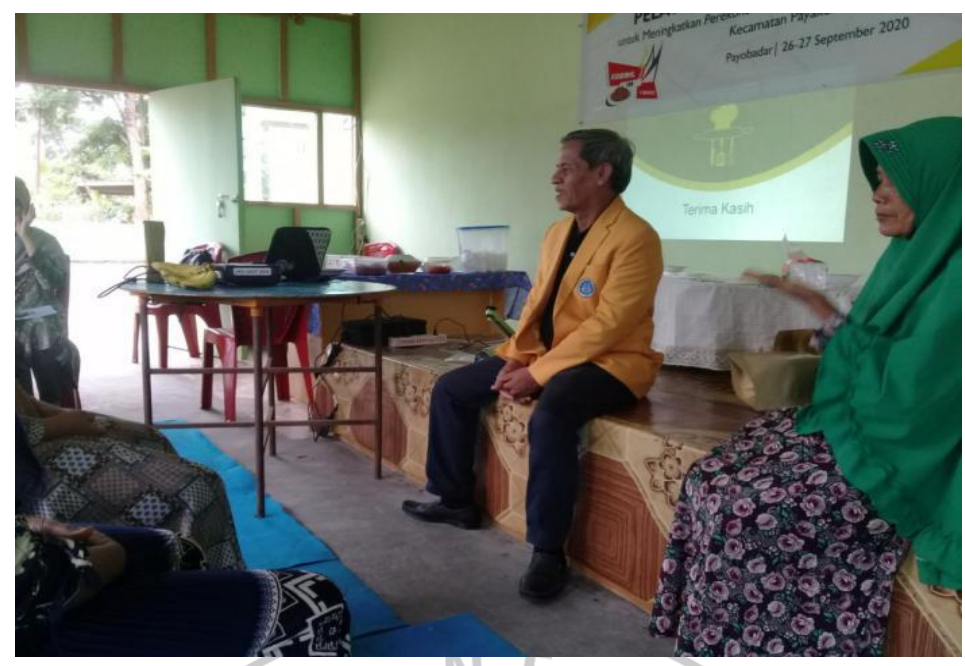

Gambar 4. Ketua Tim Pengabdian Bapak Dr. Wahudul Basri, M.Pd. memberikan Pengarahan dalam Pelatihan Usaha Rendang Rumahan.

Berikutnya masuk kepada kegiatan pembuatan rendang, Kelompok Mitra pengabdian yang diketua oleh Ibuk Yurdalis bersama anggotanya mendemonstrasikan pembuatan rendang mulai dari mempersiapkan bahan utama yakni daging dan santan kelapa. Agar rendang dapat dihasilkan dengan kualitas tinggi, maka daging yang dipesan juga yang berkuliatas baik dan segar, maka untuk itu daging yang akan dimasak diambil pada pagi hari Minggu tersebut di tempat penjualan daging yakni di Pasar Ibuh Kota Payakumbuh. Begitu juga dengan santan kelapa harus baik dan segar, maka santan untuk membuat rendang tersebut juga dipesan pada pagi hari Minggu itu juga. Setelah bahan utama yakni daging dan santan kelapa tersedia, lalu dilanjutkan oleh mitra pengabdian meracik bumbu yang telah dipersiapkan sebelummnya, selanjutnya dimulailah memasak rendang. Waktu yang dibutuhkan untuk memasak rendang ini lebih kurang 4-5 jam, tepat pada pukul 13.00 rendang masakan mitra pengabdian yang diketuai oleh Ibuk Yurdalis ini telah matang dan siap untuk dihidangkan kepada peserta pelatihan. Setelah makan bersama, dan setelah rendang dirasa agak dingin maka dilanjutkan dengan memasukan rendang ke dalam kemasan yang sudah disiapkan dengan sampel untuk ukuran $1 / 4 \mathrm{~kg}$.

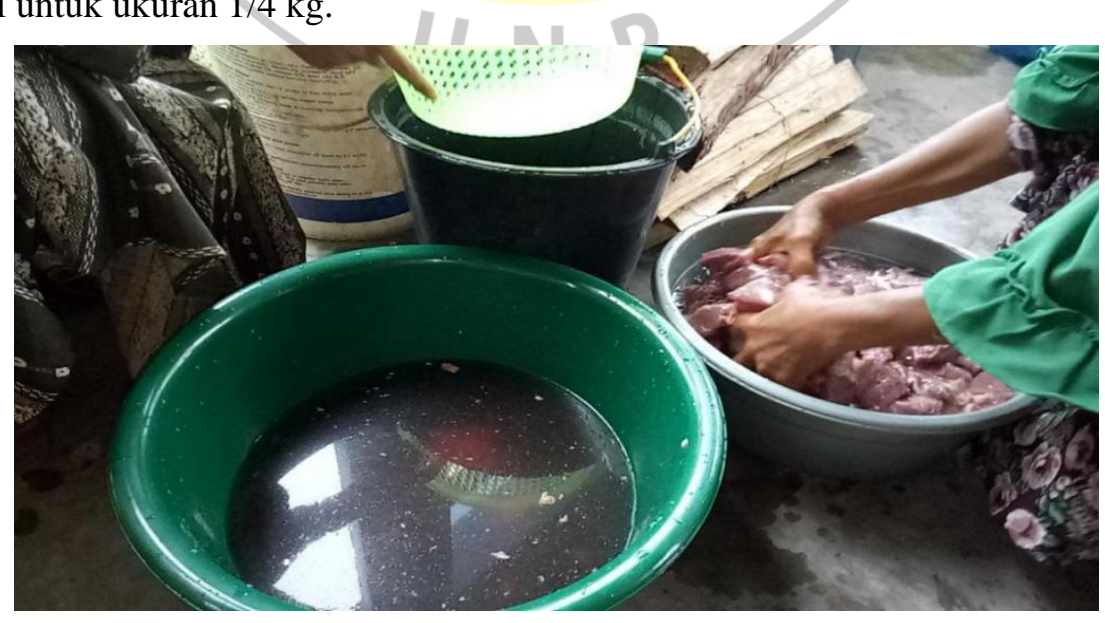

Gambar 5. Kelompok Mitra Pengabdian yang diketuai oleh Ibuk Yurdalis Memulai Masakan Rendang 
Rusdi Rusdi, Wahidul Basri, Etmi Hardi, Heffi Alberida Usaha Rendang Rumahan Untuk Meningkatkan Perekonomian Keluarga di Kelurahan Padang Tangah Payobadar Kecamatan Payakumbuh Timur

Selanjutnya pada pukul 14.00 masuk kepada kegiatan Pelatihan Pemasaran Online. Sebelum Pelatihan dimulai, Tim Pengabdian UNP menyampaikan tujuan dari pelatihan pemasaran rendang online ini. Kalau untuk membuat rendang Ibu-Ibu sudah ahli karena sudah sering membuat rendang. Akan tetapi kalau untuk pemasaran usaha rendang membutuhkan kiat tersendiri untuk memasarkannya. Untuk memasarkan secara tradisional atau langsung ke pelanggan atau pelanggan yang membeli ke toko kita itu sudah hal yang biasa. Namun memasarkan rendang secara online untuk Ibu-Ibu yang ingin membuka usaha rendang membutuhkan keahlian tersendiri, maka untuk itulah diperlukan pelatihan ini agar Ibu-Ibu dapat membuka usaha rendang atau usaha yang lainnya dan dapat mengembangkan pemasarannya secara online melalui berbagai media sosial yang berkembang saat ini.

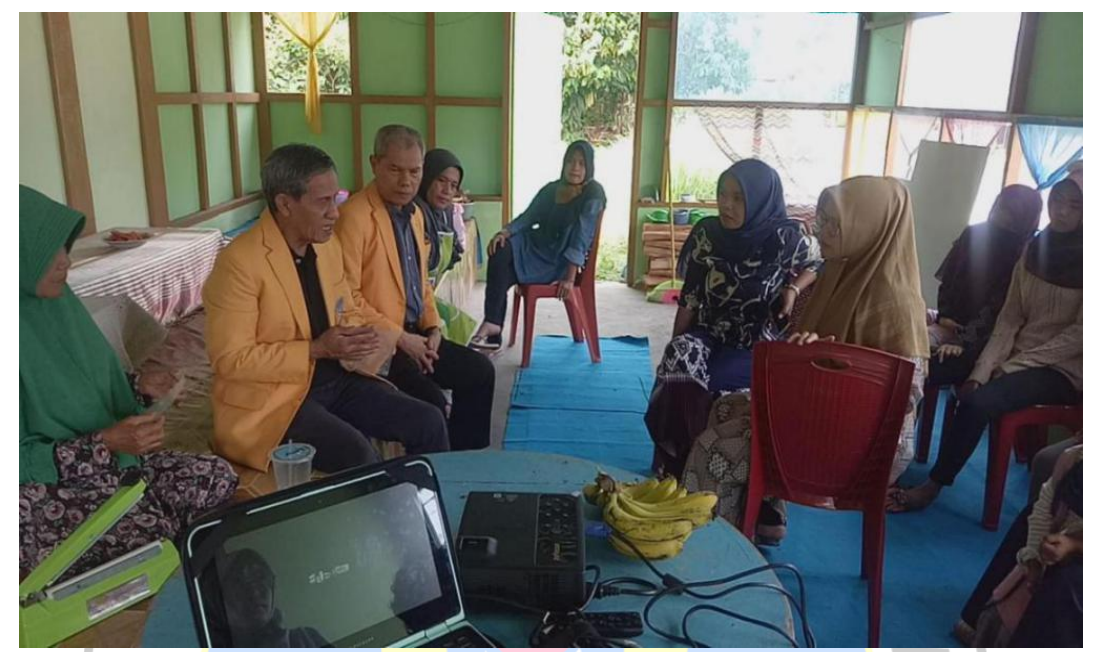

Gambar 6. Tim Pengabdi memberikan arahan dalam Pelatihan Pemasaran Online Usaha Rendang.

Selanjutnya penyampaian materi pelatihan usaha pemasaran rendang online disampaikan oleh Sherly. Paltform Pejualan dan Pembelian Online: (1) Marketplace: Marketplace adalah sebuah website yang menghubungkan seorang penjual dengan pembeli melalui internet. Marketplace sebenarnya memiliki konsep yang mirip dengan pasar tradisional. Jika calon pembeli memang mau membeli barangnya, mereka bisa melakukan pembayaran melalui marketplace itu sendiri. Penjual hanya perlu mendaftarkan diri dan mereka sudah bisa mulai berjualan. (2) Online Shop: Online Shop mengacu pada berbagai toko yang ada pada platform online, online shop tidak harus ada pada website. Untuk melakukan pemasaran, pembeli bisa menghubungi penjual lewat aplikasi chat seperti WhatsApp atau line. Berbeda dengan marketplace, jika berjualan di online shop, penjual akan berhubungan langsung dengan pembeli. Kemudian pembeli melakukan pembayaran melalui transfer, kirim bukti pembayaran dan penjual akan mengirim barang ke alamat. Contoh aplikasi yang dapat dimanfaatkan untuk membuka online shop: WhatsApp, Instagram, Facebook dll.

Selanjutnya Anggela menyampaikan materi: "Praktek memasukkan aplikasi ke HP Ibu-Ibu peserta pelatihan". (1) Cara memanfaatkan Instagram: nama akun, deskripsi pada ruang bio akun instagram, foto profil menarik dan berkesuaian dan isi konten akun instagram. (2) Cara memanfaatkan Facebook: buat halaman facebook khusus bisnis, lakukan, promosi menggunakan facebook ADS, temukan teman yang sesuai dengan bisnis kita, seringlah membuat postingan, dan berikan testimoni terhadap produk kita. (3) Cara memanfaatkan WhatsApp: caption, hastag, berintekaksilah dengan pengguna lainnya, lakukan endorsment. (4) Cara memanfaatkan toko di platform shopee: daftar akun shopee, buka situs resmi shopee di browser/dounload APK shopee di playstore, buka dan atur toko, atur alamat toko dan jasa pengiriman, mulai berjualan, masukkan rincian produk, toko siap berjualan.

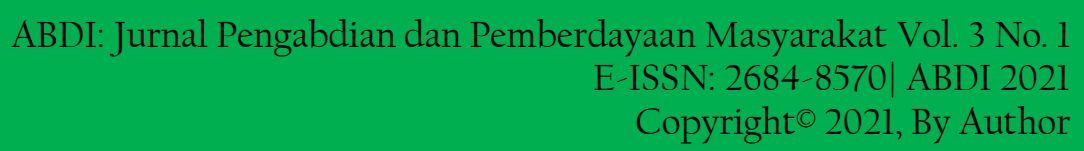


Rusdi Rusdi, Wahidul Basri, Etmi Hardi, Heffi Alberida Usaha Rendang Rumahan Untuk Meningkatkan Perekonomian Keluarga di Kelurahan Padang Tangah Payobadar Kecamatan Payakumbuh Timur

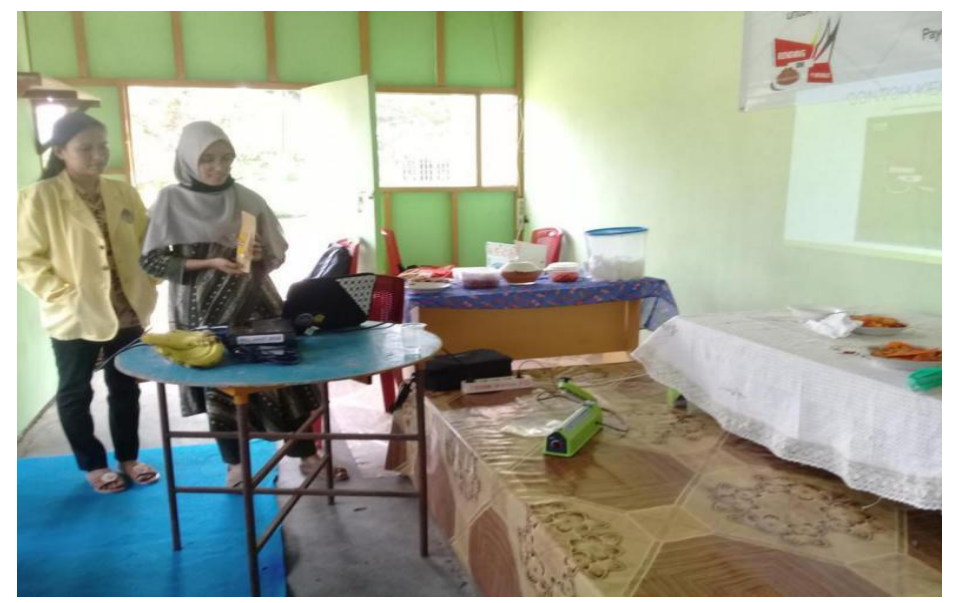

Gambar 7. Sherly dan Anggela memberikan materi Pelatihan Paltform Pejualan dan

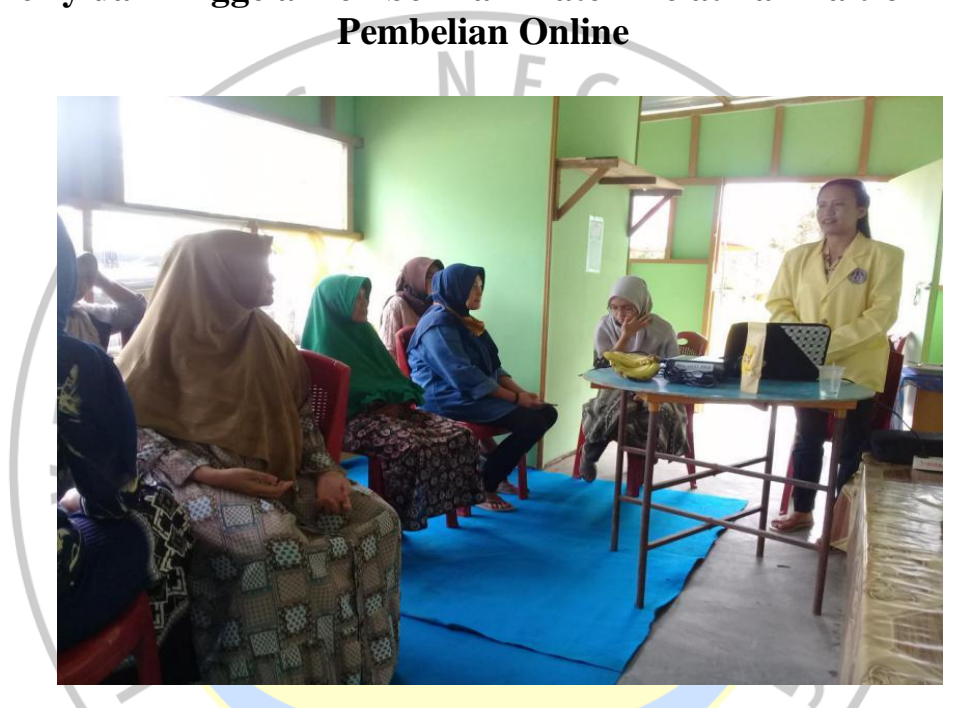

Gambar 8. Memasukkan aplikasi pemasaran online ke HP Ibu-Ibu peserta pelatihan.

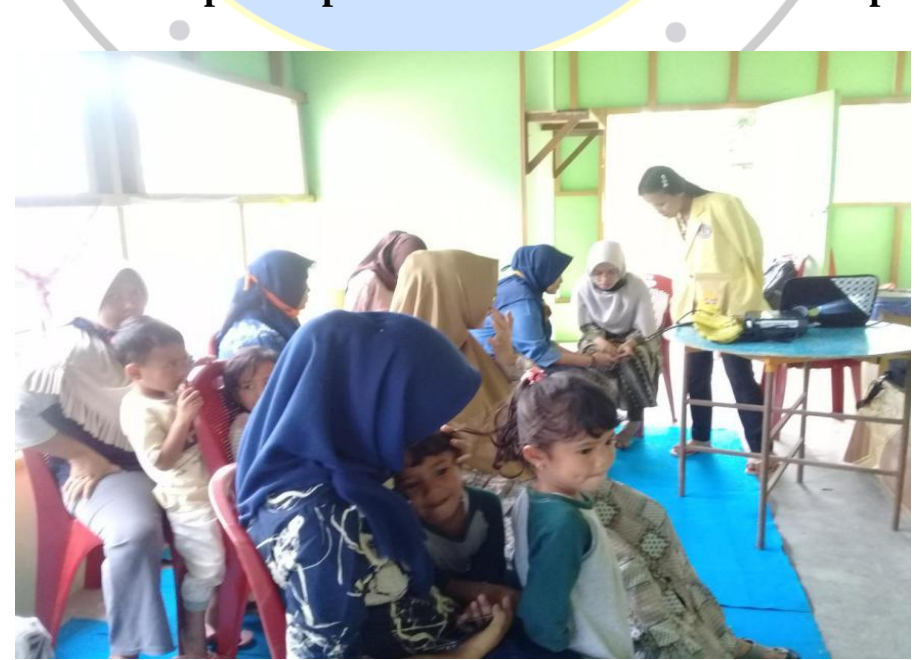

Gambar 9. Ibu-Ibu peserta pelatihan sedang mempraktekkan pemasaran online usaha rendang. 
Rusdi Rusdi, Wahidul Basri, Etmi Hardi, Heffi Alberida Usaha Rendang Rumahan Untuk Meningkatkan Perekonomian Keluarga di Kelurahan Padang Tangah Payobadar Kecamatan Payakumbuh Timur

Pelatihan pemasaran usaha rendang rumahan ini mendapat respon yang cukup positif dari para peserta, hal ini terlihat dari antusias dan keseriusan para peserta mengikuti pelatihan sebanyak 15 orang mulai dari awal sampai berakhirnya kegiatan. Kegiatan pelatihan usaha rendang ini yang sudah dimulai sejak pukul 09.00 pagi selesai pada pukul 16.00 sore.

\section{Kesimpulan}

Pelatihan usaha rendang di Kelurahan Padang Tangah Payobadar Kecamatan Payakumbuh Timur mendapat respon positif dari masyarakat. Hal ini nampak dari antusiasnya para Ibu-Ibu mengikuti kegiatan dari awal sampai kegiatan berakhir. Usaha rendang rumahan oleh kelompok Mitra yang diketuai oleh Ibuk Yurdalis bisa berkembang jika tidak hanya mengandalkan pesanan tetapi juga mengupayakan pemasaran secara online melalui berbagai media sosial. Usaha rendang rumahan dengan pemasaran online yang dilakukan oleh kelompok Tim Mitra dari UNP juga bisa dilakukan oleh anggota masyarakat lainnya terutama Ibu-Ibu yang ikut pelatihan usaha rendang ini.

\section{Daftar Pustaka}

Erwin, L. (2013). Aroma Rasa Kuliner Indonesia, Aneka Olahan Rendang. Jakarta: Gramedia Pustaka Utama.

Hanafiah, H., Saputra, R. , \& Ramadhanty, G. S. (2019). Rendang, Merantau, dan Minangkabau: Relevansi Masakan Rendang dengan Filosofi Merantau Orang Minang. Jakarta: Gramedia Pustaka Utama.

Suri, R. A. (2012). Rendang Traveler: Menyingkap Brttuahnya Rendang Minang. Jakarta: Terran ink. Utomo, B. (2012). Rendang; Juara Masakan Terlezat Sedunia Versi CNN Go. Jakarta: Kawan Pustaka.

Wynda, D. A. (2019). Randang Bundo. Jakarta: Gramedia Pustaka Utama.

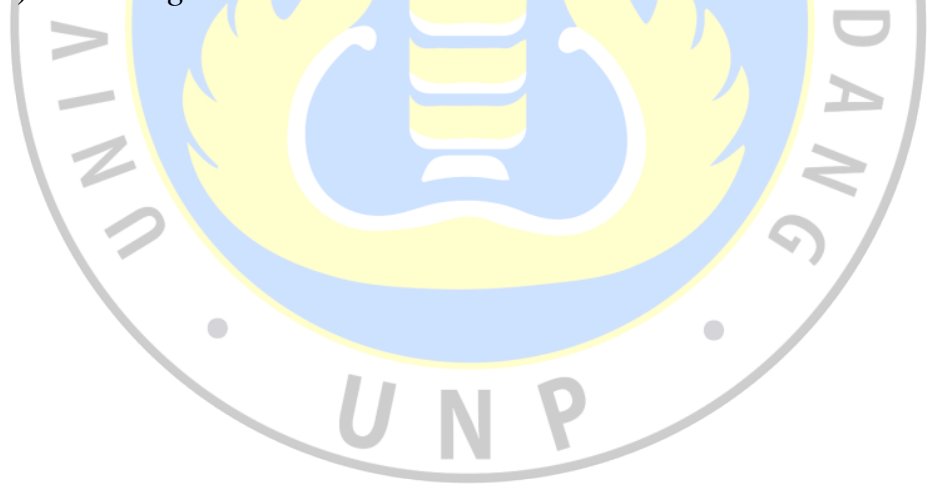

